\title{
Situational cues and correlation between CS and US as determinants of the conditioned emotional response ${ }^{1}$
}

CAROL S. DWECK and ALLAN R. WAGNER, Yale University, New Haven, Conn. 06510

Administering unsignaled USs during daily CER training sessions interfered with CER conditioning, as has frequently been reported. This effect was reduced, however, when additional daily sessions were administered during which $S_{s}$ were simply exposed to the experimental environment in the absence of the CS and US. The results indicate that $S$ 's treatment with respect to "situational" cues is important in the determination of CS.US contingency effects, and are in agreement with recent formulations of Wagner (in press, a) and Rescorla (in press) which emphasize that the degree of conditioning to a CS depends upon the associative strength of the constellation of cues in which the CS is imbedded during training.

The acquisition of a conditioned emotional response (CER) to a $\mathrm{CS}$ is interfered with when the aversive reinforcement is administered during training in the absence of the CS. Rescorla (1968) has demonstrated a systematic relationship, whereby conditioning approaches zero as the probability of reinforcement in the absence of the $\mathrm{CS}$ is made to approach the probability of reinforcement in the presence of the CS.

While such findings support other data (e.g., Rescorla, 1966, 1967) which indicate that the correlation between CS and US occurrence is empirically an important determinant of Pavlovian conditioning, further information is necessary to allow an adequate theoretical interpretation of this effect.

One simple possibility would be that reinforcement, given in an interval between CS-US conditioning trials, interferes with the conditioning which occurs on the immediately adjacent trials. For example, an unsignaled reinforcement shortly after a CS-US trial might interfere with the consolidation of learning on that trial. Or, an unsignaled reinforcement shortly before a CS-US trial might interfere with the adequate perception of the CS on that trial. Increasing the probability of reinforcement in the absence of the CS would increase the likelihood of reinforcement occurring in either of these positions of potential interference with conditioning.
Wagner (in press, $a, b$ ) and Rescorla (in press) have proposed another possibility. The major assumption is that the changes in associative strength of a cue, consequent to reinforcement or nonreinforcement, are a function of the associative strength of the entire constellation of stimuli occurring at the time of reinforcement or nonreinforcement: To the degree that the stimulus complex is already maximally behaved toward as signaling reinforcement, further reinforcement is assumed not to lead to an increase in this "excitatory" tendency for any of the component cues; to the degree that the stimulus complex is already maximally behaved toward as signaling nonreinforcement, further nonreinforcement is assumed not to lead to an increase in this "inhibitory" tendency for any of the component cues.

Such a theory can account for various findings involving experimentally constituted compound stimuli (e.g., Kamin, in press; Wagner, in press, $a, b)$. In order similarly to account for S's sensitivity to the correlation between $C S$ and US, as demonstrated in the Rescorla experiment, it is necessary to acknowledge that the CS occurs in compound with many "situational" cues, which by virtue of their occasional pairing with reinforcement should acquire associative strength, i.e., should become fear-producing in the CER situation. When reinforcements are administered in the absence of the $\mathrm{CS}$, in addition to those in the presence of the CS, the situational cues should become more fear-producing. Thus, it is possible to assume (e.g., Wagner, in press, b; Rescorla, in press) that the more fear-eliciting are the situational cues, and hence the compound of CS plus situational cues, the smaller should be the increment in fear accruing to the CS on each reinforced trial, and the larger should be the decrement in fear accruing to the CS on each nonreinforced trial.

The present experiment was designed to provide further information relevant to the above interpretations. Basically, the design involved giving all Ss a single daily CER conditioning session during which a CS was paired with a US on a partial reinforcement schedule. For half of the Ss, the US was otherwise never delivered, thus providing a high correlation between the CS and US occurrences. For the remaining Ss, during this daily conditioning session, the US was additionally presented with the same relative frequency in the absence of the CS as in its presence, thus reducing the correlation between the CS and US occurrences. Half of the Ss experiencing each of these conditions of correlation received no further treatment each day, and hence were similar to groups compared by Rescorla (1968). The other half of the Ss experiencing each condition of CS-US correlation during the CER training session received four additional sessions in the experimental environment each day during which they received no CSs or USs.

According to the local interference interpretation, additional sessions in the experimental environment should have no special influence on CS effectiveness. The administration of additional sessions involves no change in the location of the unsignaled reinforcements with respect to the conditioning trials, and therefore should not remove the acquisition decrement due to the unsignaled reinforcements. In contrast, according to the Wagner and Rescorla positions, such sessions should serve to extinguish S's fear of situational cues resulting from unsignaled reinforcement and therefore should serve to increase the acquisition of fear to the CS.

\section{SUBJECTS}

The Ss were 32 male albino rats, obtained from the Charles River Breeding Laboratory, and were 100-130 days old at the start of the experiment.

\section{APPARATUS}

Training and testing were conducted in four operant-conditioning chambers, with floors constructed of 1/8-in.-diam stainless steel rods, $1 / 2$ in. apart. A reservoir containing $10 \%$ sucrose solution was mounted on an outside wall of each box and was connected to a glass drinking tube which extended

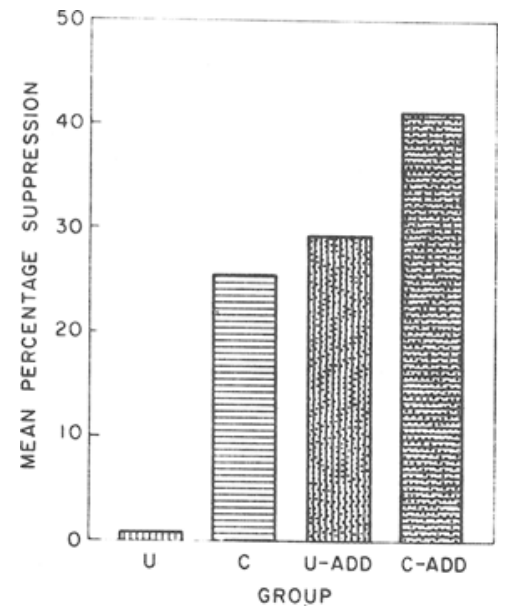

Fig. 1. Mean percentage suppression to the CS over the 2 days of extinction testing, for the four experimental groups. 


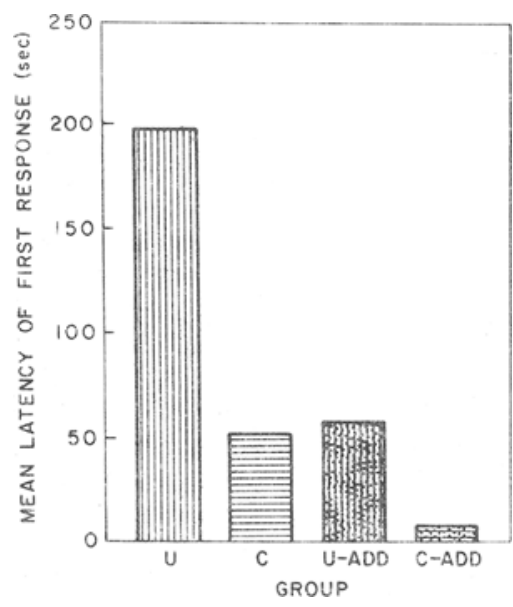

Fig. 2. Mean latency in seconds, of the first licking response on the day following the termination of CER training, for the four experimental groups.

$1 / 4$ in. into the box. The orifices in the drinking tubes were equated for size and yielded approximately $1 \mathrm{ml}$ of solution per 600 licks. The drinking tube and the bars of the grid were connected via a contact relay such that each lick advanced a cumulative recorder and a printing counter.

The CS was of $2 \mathrm{~min}$ duration and consisted of either an intermittent lighting of two $3-\mathrm{W}, 120 \mathrm{~V}$ chamber lamps at the rate of three flashes per second, or a $2,500-\mathrm{Hz}$ tone. The light served as the CS for half of the Ss in each experimental group, while the tone served as the CS for the remaining Ss. The US was provided by a Grason-Stadler shock generator with nominal settings at $.5 \mathrm{sec}$ and $1 \mathrm{~mA}$ and was scrambled through the grid floor.

\section{PROCEDURE}

All Ss were deprived of food and water for 2 days prior to the beginning of the experiment and thereafter were given access to water $1 \mathrm{~h}$ a day and sufficient food during that time to maintain them at $75 \% .80 \%$ ad lib body weight. Training and testing were conducted in 10 consecutive days. On Days 1 and 2 , Ss were trained to drink the sucrose solution during single daily sessions. Over the following 5 days, access to the drinking tube was prevented by a Plexiglas shield and CER conditioning was administered. One session of drinking retraining was then given, prior to two daily sessions of CER testing. All sessions throughout were $96 \mathrm{~min}$ long.

Eight $S$ s were randomly assigned to each of four groups during the conditioning phase. All groups received a daily CER conditioning session in which there were eight presentations of the $\mathrm{CS}$, four of which terminated with the US. For Groups $\mathrm{C}$ and
C-add, no other USs were administered. Thus, for these "correlated" groups, during the conditioning sessions the probability of shock was .5 in the presence of the CS and 0 in its absence. For Groups U and U-add, 20 unsignaled USs were administered in each CER conditioning session, occurring at the end of a random half of the $2 \cdot \mathrm{min}$ non-CS periods. Thus, for these "uncorrelated" groups, during the conditioning sessions, the probability of shock was the same in the absence as in the presence of the CS.

Groups $C$ and $U$ received no further treatment each day. Groups $\mathrm{C}$-add and $\mathrm{U}$-add were given four additional sessions per day during which access to the drinking tube was prevented and neither the CS nor the US was presented. For the latter groups, the within-day intersessions interval was $96 \mathrm{~min}$, with two of the additional sessions preceding and two following the daily CER conditioning session. Groups $\mathrm{C}$ and $\mathrm{U}$ were fed and watered $5 \mathrm{~h}$ after their single daily session, while Groups C-add and U-add were fed $1 / 2 h$ after their last session of the day, so as to equate the degrees of deprivation during the CER session.

During the CER conditioning sessions, the interval between the initiation of successive CSs was varied according to an irregular schedule of $8,10,14$, or $16 \mathrm{~min}$ with a mean of $12 \mathrm{~min}$. The intershock intervals were also varied, with a mean of $4 \mathrm{~min}$ for Groups $U$ and $U$-add and a mean of 24 min for Groups $C$ and $C$-add. A different sequence of $\mathrm{CS}$ and US presentations was administered on each day and all groups received the same sequence of pairings of CS with shock on a given day of training.

During CER testing, the CS was for the first time presented while Ss had access to the drinking tube. There were three CS presentations, each testing day, with a mean interstimulus interval of $12 \mathrm{~min}$. The US was never presented during the test sessions and the testing program was not begun until Ss had emitted at least 250 licks.

\section{RESULTS AND DISCUSSION}

CER conditioning was evaluated during testing in terms of the degree to which CS presentation suppressed the rate of ongoing drinking. Percentage suppression was computed according to the formula, $[(A-B) / A] \times 100$, where A represents the number of responses in the $2-\mathrm{min}$ period immediately prior to CS onset and B represents the number of responses during the CS. Thus, $100 \%$ suppression indicates complete cessation of responding in the presence of the $\mathrm{CS}$, while $0 \%$ indicates no effect of the CS.

Figure 1 presents the mean percentage suppression to the CS over the 2 days of testing for each of the four groups. As may be seen, the suppression measure was decreased when the US was presented in the absence of the CS (Groups U and U-add as compared to Groups $\mathrm{C}$ and $\mathrm{C}$-add, respectively) but was increased when additional sessions were administered in which neither the CS nor US were presented (Groups U-add and C-add as compared to Groups $\mathrm{U}$ and $\mathrm{C}$, respectively).

Consistent with the findings of Rescorla (1968), there was little evidence of conditioned suppression in Group U: the mean suppression observed was not significantly different from zero $(t=.12)$. But each of the remaining three groups did show reliable suppression, including Group C $(t=4.96$, df $=7, p<.01)$ which was treated like Group $U$, except for the omission of the US in the absence of the CS, and Group $U \cdot a d d(t=6.80, d f=7, p<.01)$, which was treated like Group $U$, except for the additional exposures to the experimental chamber each day. While Group C-add showed the greatest suppression, it did not differ significantly from either Groups C or U-add. Group comparisons utilizing the overall within-group mean square as the error estimate revealed reliable differences in percentage suppression only in the case of those contrasts involving Group U. That is, Group U suppressed significantly less than did Group C, Group U-add, or Group C-add $(t=1.82, t=2.13, t=3.00$, respectively; $\mathrm{df}=28, \mathrm{p}<.05)$.

As an index of the fear of situational cues following CER training, a measure was taken of the length of time which elapsed between $S$ 's placement in the experimental chamber and the occurrence of the first lick response on the drinking retraining day. It may be expected that the greater the fear aroused by the situational cues, the longer should be the delay before the start of drinking.

Figure 2 depicts the mean response latency for each of the four groups. As may be seen, the group relationships are essentially the inverse of those in Fig. 1. According to this measure, fear aroused by the situational cues was increased when the US was presented in the absence of the CS (Groups $\mathrm{U}$ and $\mathrm{U}$-add as compared to Groups $C$ and $C$-add, respectively) and decreased when additional sessions were administered in which neither the CS nor the US was presented (Groups U-add and $\mathrm{C}$-add as compared to Groups $U$ and $C$, respectively). As in the case of the suppression measure, however, the only contrasts to reach statistical significance involved Group U. That is, Group U took significantly longer to begin drinking than did Group C, Group U-add, or Group C-add $(t=2.40, t=2.27, t=3.12$, respectively; $\mathrm{df}=28, \mathrm{p}<.05)$. 
This pattern of findings is consistent with the notion that unsignaled US interfere with CER conditioning to the degree that they increase S's fear of situational cues in the context of which the CS is trained. When this fear is diminished by additional exposures to the situational cues in the absence of the US, the interfering effect of the unsignaled USs upon CER conditioning is also diminished.

The theoretical formulations of Wagner (in press, $a, b$ ) and Rescorla (in press), which have been grossiy summarized, anticipate such effects. Any procedure which is successful in increasing the fear-producing properties of those cues with which the CS is presented in compound would be expected to result in smaller increments in the CER to the CS on reinforced trials, and in larger decrements in the CER to the CS on nonreinforced trials. Any procedure which is successful in decreasing the fear-producing properties of those cues with which the CS is presented in compound would be expected to result in larger increments in the CER to the CS on reinforced trials, and in smaller decrements in the CER to the CS on nonreinforced trials.

The present findings would not be predicted by a local interference interpretation of the influence of unsignaled USs. It might be suspected, however, that unsignaled USs simply reduced the overall rate of drinking during the test session, so that the CS only appeared less effective in Group $U$ as a consequence of being evaluated upon an already depressed and insensitive base-line. It is important, then, to note that following the drinking retraining day there were no longer any detectable systematic differences in behavior among the four groups in the absence of the CS, and that the low suppression measure to the CS in Group $U$ during testing was associated with a higher absolute number of lick responses during the $C S(M=378)$ than was observed in any of the remaining three groups $(M=318,306$, and 256$)$. It thus appears that the critical variable in the present experiment was the fear engendered by the situational cues during conditioning rather than during testing.

Regardless of the theoretical interpretation, the present findings are clear in revealing a contextual dependence in the influence of CS-US contingencies. There was no difference in the correlation between CS and US occurrence in Groups $U$ and $U$-add, as computed within the daily CER conditioning session. Since neither of these groups was exposed to either the CS or US outside of this daily conditioning session, there was also no difference in the correlation between CS and US occurrence as compuied over $S$ 's entire daily experience.

What did differ was the degree of correlation between CS and US occurrence in Groups $U$ and $U$-add as computed over the total time spent in the experimental chamber. There was, therein, a considerably higher correlation in Group U-add than in Group $\mathrm{U}$, as the additional sessions served to reduce the overall relative frequency of US occurrence in the absence of the CS.

Thus, the different degrees of suppression observed in Groups $U$ and $U$-add may be viewed as consistent with the different CS-US correlations which were arranged in the two groups. But such a view requires an explicit recognition of the role played by those contextual cues which define the experimental environment within which these correlations are computed.

\section{REFERENCES}

KAMIN, L. J. Predictability, surprise, attention, and conditioning. In B. Campbell and R. Church (Eds.), Punishment and aversive behavior. New York: Appleton-Century-Crofts, in press.
RESCORLA, R. A. Predictability and number of pairings in Pavlovian fear conditioning. Psychonomic Science, 1966, 4, 383-384.

RESCORLA, R. A. Pavlovian conditioning and its proper control procedures. Psychological Review, 1967, 74, 71-80.

RESCORLA, R. A. Probability of shock in the presence and absence of $C S$ in fear conditioning. Journal of Comparative \& Physiological Psychology, 1968, 66, 1-5.

RESCORLA, R. A.Conditioned inhibition of fear. In W. Honig and N. Mackintosh (Eds.), Fundamental issues in associative learning. Halifax, N.S.: Dalhousie University Press, in press.

WAGNER, A. R. Stimulus validity and stimulus selection in associative learning. In W. Honig and N. Mackintosh (Eds.), Fundamental issues in associative learning. Halifax, N.S.: Dalhousie University Press, in press, a.

WAGNER, A. R. Stimulus selection and a "modified continuity theory." In G. H. Bower and J. T. Spence (Eds.), The psychology of learning and motivation. Vol. 3. New York: Academic Press, in press, $b$.

NOTE

1. This research was supported in part by NSF Grant GB-6534.

\section{Reinforcement of shock-induced fighting}

PAUL I. DREYER and RUSSELL $M$. CHURCH, Brown University, Providence, R.I. 02912

Twelve rats were given a fixed number of inescapable electric shocks in a T-maze.
Under these conditions, Ss chose to run to the end of the arm containing another rat and engaged in the stereotyped shock-induced fighting. This choice supports previous studies showing that the opportunity for aggression is a 